\title{
Rosa Luxemburgo y la oposición a la Primera Guerra Mundial'
}

Carlos Tuta Alarcón ${ }^{2}$

Universidad Autónoma de Colombia

Artículo de Reflexión derivado de investigación

Recibido: 23-09-2014 Aprobado: 21-II-2014

\section{Resumen}

En este trabajo se busca establecer el contexto en que Rosa Luxemburgo tuvo que actuar durante las dos últimas décadas de su vida (1898-1919), para convertir el movimiento de los trabajadores de Alemania y de la periferia polaca del imperio de los zares, en el sujeto colectivo de la transformación social. No obstante, el desafío mayor se presentó cuando estalló la primera guerra mundial y puso a prueba la teoría y la práctica política del movimiento obrero europeo.

Palabras clave: Sujeto histórico, movimiento obrero, Primera Guerra Mundial, paz.

\section{Rosa Luxemburg and opposition to the First World War}

\section{Abstract}

In this work we search to establish the context in which Rosa Luxemburgo had to play a role during the last two decades of her life (1898-1919), to make become the movement of the Germany's workers and the Polish periphery from the Tsars Empire, in a collective subject of social transformation. Even though,

I Este artículo es resultado del seminario sobre el centenario de la Primera Guerra Mundial, realizado por el Depto. de Historia de la Universidad Nacional de Colombia y la Carrera de Historia de la Universidad Autónoma de Colombia, en agosto de 20 I 4.

2 Magister en Análisis de Problemas Económicos, políticos y de Relaciones Internacionales, del Instituto de Altos Estudios para el Desarrollo, Universidad Externado de Colombia. Profesor de la U. Autónoma y de la Maestría en DDHH de la UPTC (sede Chiquinquirá). Dirección electrónica: luciotuta@yahoo.es 
the big challenge was presented when the First World War broke out and it makes real the theory and political practice of European labourer movement.

Key words: Historical subject, labourer movement, First World War, peace.

\title{
Rosa Luxemburgo e a oposição à Primeira Guerra Mundial
}

\begin{abstract}
Resumo
Neste trabalho busca-se estabelecer o contexto no qual Rosa Luxemburgo teve que atuar durante as duas últimas décadas de sua vida (|898-1919), para converter o movimento dos trabalhadores de Alemanha e da periferia polaca do império dos Zares, no sujeito coletivo da transformação social. No entanto, o maior desafio se apresentou quando explodiu a Primeira Guerra Mundial e colocou à prova a teoria e a prática política do movimento operário europeu.
\end{abstract}

Palavras chave: Sujeito histórico, movimento operário, Primeira Guerra Mundial, paz.

Permítanme empezar con una idea que debemos al gran historiador del siglo XX, Eric Hobsbawm, sobre las fuentes de la barbarie de los últimos 100 años. De 1914 a la actualidad. "El siglo XX corto" empezó en 1914 con un período de guerras y catástrofes que llegó hasta 1945, con el fin de la II guerra mundial. Vino luego un período de tregua hasta los años 90 y de nuevo estamos viviendo un nuevo período de guerras y catástrofes humanitarias, como todas las que hemos estado viendo por televisión durante los últimos veinticinco años.

Pero esta barbarie se inició con la Primera Guerra Mundial, cuando se rompieron todas las reglas de conducta moral de los Estados de las grandes potencias que debían observar en sus relaciones interiores y exteriores, traicionando además los ideales del movimiento cultural de la llustración que les había dado origen. ${ }^{3}$

La guerra de las trincheras acostumbró a los políticos y a los jefes militares a enviar a la muerte segura a miles de jóvenes en un solo combate, con tal de que en el otro bando murieran otros miles y a veces millones. En la batalla por Verdún, febrero- junio de 1916, se enfrentaron dos millones de hombres y pereció un millón. En el Somme la Gran Bretaña envió a la muerte a 420.000 de sus soldados ${ }^{4}$ Se usaron armas prohibidas, armas químicas y después del conflicto, una de las cosas más impresionantes eran las casas para jóvenes soldados, ciegos por el conflicto. Durante la larga guerra de las trincheras, había que enterrar a los muertos allí mismo y convivir con las ratas y los piojos, en tales condiciones muchos perdían la razón.

3 Hobsbawm, Eric. La barbarie: guía del usuario. En: Sobre la Historia. Editorial Crítica. Barcelona. 1998, pág. 253.

4 Hobsbawm, Eric. Historia del Siglo XX. Editorial Crítica, Grijalbo, Mondadori. Buenos Aires. 1998, págs. 33 y 34. 
En la actualidad es necesario reconocer la deuda que la humanidad tiene con todas aquellas personas que lucharon a riesgo de su propia vida para que la gran guerra no se produjera y que buscaron maneras de evitarla. Es el caso de Rosa Luxemburgo, quien además pensó -siguiendo a Marx- una nueva sociedad, que por sus propias características no necesitara de la guerra.

Por esta razón, fue ella quien planteó la alternativa del socialismo o la barbarie y al final de la Primera Guerra Mundial, impulsó la organización de los Consejos de Obreros y Soldados, en medio de la revolución alemana para iniciar la construcción del socialismo y la extinción del Estado.

De esa alternativa planteada hace 100 años, el capitalismo imperialista impuso la barbarie, que en la época actual resulta peor porque nos la presentan como espectáculo por televisión, fenómeno que moldea las subjetividades, para que nos acostumbremos a la brutalidad y la veamos como algo normal. Por todo ello, el ejemplo de Rosa Luxemburgo, es actual. Entre otras cosas, ella junto con Clara Zetkin reunieron un congreso de mujeres en 191 I contra la guerra y entre sus propuestas incluyeron celebrar el 8 de marzo como día internacional de la mujer, como el símbolo más bello de la vida.

Rosa Luxemburgo resulta una mujer muy atractiva para América Latina, porque nació y empezó a luchar en la periferia colonial del inmenso imperio de los zares, en Zamosc, una ciudad pequeña de Polonia, el 5 de marzo de 187।, el año de la Comuna de Paris. Creció en Varsovia en la familia de un mediano empresario de la madera que tenía cinco hijos, dos mujeres y tres hombres siendo ella la más pequeña. Su padre judío alemán, le transmitió el idioma y la cultura de Goethe y Schiller. Hablaba entonces polaco, ruso, alemán, inglés y francés.

En su patria repartida entre tres imperios, desde adolecente pensó y escribió contra esos grandes poderes. A los 16 años ingresó al primer grupo revolucionario, y por causa de esa actividad muy pronto se vio en el exilio.

En la universidad de Zurich, en Suiza junto a otras brillantes jovencitas se preparó intensamente en lo intelectual, vinculando siempre cada nuevo conocimiento a la actividad práctica.

Su tesis de grado fue sobre "El desarrollo industrial de Polonia", tema que nos indica el arraigo a su país, donde actuando en consecuencia contribuye a la organización del Partido socialista Polaco (PSP) y comienza a publicar un periódico junto con Julián Marchevsky y Leo Jogiches, quien va a ser su compañero de muchos años. El Partido socialista Polaco (SP) fundado en 1892, dio origen dos años después a una disidencia encabezada por Rosa y sus amigos llamada Socialdemocracia del reino de Polonia y Lituania (SDKPiL). La disidencia se produjo porque no concebían un Estado polaco independiente, ya que ello le daría la hegemonía a la burguesía nacionalista y se debilitaría el frente anticapitalista que debía construirse en los tres imperios: ruso, alemán y austriaco. Esta parece ser una de las fuentes de la oposición de Luxemburgo al derecho de las naciones a la autodeterminación, equivocación justamente criticada por Lenin.

Leo Jogiches, también judío, de las capas acomodas de Lituania, había desertado del ejército del Zar y se había vinculado con Rosa desde cuando ella era estudiante en Zurich. Su talento como organizador y su compromiso habían impresionado a la joven y su relación de pareja duró hasta 1906, 
pero siguieron luchando juntos hasta 1919, año en que cayeron asesinados tras la temible represión que siguió a la revolución alemana.

Los jóvenes de la periferia de los imperios se sentían atraídos por la patria de Marx y sobre todo por los avances del movimiento obrero alemán, dirigido por Augusto Bebel. Los estudios de economía y de historia de Luxemburgo también la inclinaban a trabajar en el centro del imperio. Por ésta razón, para obtener la nacionalidad alemana, requisito indispensable para poder participar en la acción política, se casó con Gustav Lubeck de ese país, hijo de la familia donde residía en Zurich, de quien se divorció de inmediato, pero sus papeles llevaban ya ese apellido y podía ingresar para luchar en la Alemania del káiser Guillermo II.

Para hacernos una idea del contexto político, es necesario tener en cuenta que el Antiguo Régimen no había terminado de caer en la Europa anterior a la guerra, por un lado, todavía era muy agraria y monárquica, Inglaterra Alemania y Rusia, poseían una nobleza poderosa. ${ }^{5}$ Ciertos elementos del antiguo régimen se constituían en "la esencia misma de las sociedades civiles y políticas presentes en Europa $^{6}$ y, por otro lado, el avance económico de la burguesía, se compensa con el mantenimiento del poder político y los valores de la aristocracia.7 Todo en medio de una configuración internacional determinada por la nueva etapa de avance imperialista y su lucha por el reparto del mundo. Uno de los actores principales de este drama, Carlos Liebknecht señaló que en las condiciones "semiabsolutistas, semifeudales" de la Alemania de la época, el militarismo "había alcanzado gran amplitud", tanto que este militarismo prusiano germano "no era solamente un Estado dentro del Estado, sino más exactamente un Estado por encima del Estado"8

En este marco internacional, se busca en la primera parte, establecer que Rosa Luxemburgo dedicó las dos últimas décadas de su vida (1898-1919) a una brillante praxis revolucionaria, dirigida a transformar a los trabajadores de Alemania y del imperio de los zares en el Sujeto colectivo de la revolución socialista. Sin embargo, el desafío mayor se presentó cuando el estallido de la primera guerra mundial puso a prueba el movimiento obrero, en un momento en que este se encontraba dividido en tres grandes escuelas teóricas y políticas.

En la segunda parte, se observa la oposición a la primera guerra mundial utilizando la propuesta de la nueva herramienta de la huelga política general.

La última parte se refiere a la revolución alemana y el interés de la autora por la democracia de los consejos.

5 Kofler, Leo. Contribución a la historia de la sociedad burguesa. Amorrortu Editores, Buenos Aires, I97I, pág. 313.

6 Mayer, Arno. La persistencia del antiguo régimen. Europa hasta la gran guerra. Alianza Editorial, Madrid, 1984, pág. 122.

7 Elias, Norbert. La sociedad cortesana. Fondo de Cultura Económica. Méjico. 1996.

8 Liebknecht, Carlos. Militarismo, guerra, revolución. Ediciones Roca No. 4I, Méjico, 1974, pág. 21. 


\section{Rosa Luxemburgo: transformar el movimiento obrero en el sujeto colectivo de la revolución ${ }^{9}$}

En 1898 Rosa Luxemburgo se trasladó a Alemania, país que con su "industrialización tardía" se había convertido en uno de los centros de la economía mundial. De este país le atraía la enorme influencia del Partido Social Demócrata (PSD), que se reclamaba marxista y aparecía como el líder de la II internacional, no sólo por su poder político sino por su aporte a la teoría revolucionaria.

Ya en Alemania ingresa al PSD, uno de los más grandes del mundo, y de inmediato se encarga de la campaña electoral entre los trabajadores de la Alta Silesia, donde habían tres millones de Polacos, allí realizó un trabajo extenuante, habló en los dos idiomas, tradujo textos y obtuvo gran éxito vinculando la lucha electoral y social con el objetivo del socialismo. Este trabajo la acercó a muchos líderes obreros que la acompañaron haciéndole frente a la policía, que prohibía las reuniones electorales, los hostigaba y detenía. Su verdadero amor, Leo Jogiches que se había quedado en Zurich atendiendo el trabajo hacia Polonia, recibía una información permanente de Rosa y por eso su correspondencia de esa época, es una fuente histórica sobre la actividad de esta insigne mujer.

\section{El marco teórico y político que enfrenta Rosa Luxemburgo}

Rosa Luxemburgo va a descubrir muy pronto las profundas grietas teóricas, ideológicas y políticas que dividían al PSD. Ocurría que al final del siglo XIX, había varios temas de fondo que no estaban suficientemente estudiados por el Marxismo, en un momento en el que se estaban produciendo cambios en la estructura del capitalismo de la libre competencia, hacia el capitalismo monopolista. Se puede decir que se vivía una crisis del Marxismo que se expresaba violentamente en el movimiento obrero. El propio Marx se había visto obligado a redactar ese texto esencial titulado: "Crítica del Programa de Gotha", luego del congreso de unificación del PSD, ante los serios problemas de comprensión teórica que se manifestaron. Problemas que se agudizaron después del congreso de Erfurt y sobre todo luego de la muerte de los fundadores del Marxismo.

El supuesto albacea de la herencia teórica fue Karl Kautsky, quien había estudiado "El problema agrario", con cierto éxito, pero cometió una serie de graves errores en otros campos. Por ejemplo, al analizar el capitalismo manchesteriano inglés, se dejó obnubilar por las bondades de la libre competencia, a la cual le asignó un espíritu pacifista, que sólo existió en sus deseos. Pero agregó además que la vieja colonización inglesa aristocrática y violenta habría sido reemplazada por una "nueva colonización positiva" y pacífica gracias al capitalismo manchesteriano. Un error lo llevaba al otro. Si "la nueva colonización" era pacífica y positiva, no existía entonces la necesidad de la lucha por

9 La concepción de sujeto colectivo de la revolución subyace a la teoría de Marx, en tanto primera fuerza productiva de la sociedad, portadora de la potencialidad de la transformación estructural de la economía, el Estado y la cultura. Se trata de un sujeto plural de trabajadores de la ciudad, el campo, la educación y la cultura. En la época actual, la acción y el debate incluye todas las identidades y minorías oprimidas por el sistema mundial capitalista, conformándose entonces el sujeto histórico. 
la independencia de las colonias. Con esta seudoteoría, Kautsky convirtió en polvo la hipótesis de Marx sobre la alianza del proletariado de los países desarrollados con el Movimiento de liberación de las colonias. ${ }^{10}$ Desde luego ésta ceguera de Kautsky, vuelve a manifestarse cuando se niega a ver el carácter imperialista-colonial de la Primera Guerra Mundial. Sin embargo, cuando el holandés Van Kol, defendió la tesis del colonialismo positivo, paradójicamente Kautski salió a combatirlo."

Pero ésta no iba a ser la única anomalía teórica que presentaba una revisión del Marxismo puesto que otro intelectual alemán, Eduard Bernstein, iba a plantear que no le encontraba mucho sentido a la idea del socialismo, aunque continuaba sintiéndose "de izquierda" dentro del movimiento de masas. Por esa razón uno de los primeros pleitos de Rosa Luxemburgo va a producirse con el reformismo de Bernstein.

En el periódico Neue Zeit, dirigido por Kautsky, Bernstein defendió una tesis particularmente grave: "Acepto sinceramente que encuentro poco sentido, e interés en eso que se entiende generalmente por objetivo final del socialismo. Este objetivo independientemente de lo que sea, no significa nada para mí; el movimiento lo es todo". '2 Si el socialismo no significaba nada, no tenía sentido la revolución, el movimiento economicista "sanchopancesco" lo era todo. Se trataba de un intento de revisar el marxismo, en el preciso momento que surgía el imperialismo.

Los primeros en salir a la palestra fueron el socialista inglés Belfort-Bax y Parvus (Aleksandr Helfand), quien dirigía el Sachsiche Arbeiter Zeitung, en Dresde, desde donde defiende los principios que informan al movimiento y exige a Kautsky que fije su posición como director del periódico.

En esos días se realiza el primer congreso del partido al que asiste Luxemburgo en octubre de I 898 en Stuttgart, quiere intervenir, pero le cuenta en una de sus cartas a Leo, que "Yo no podría (hacerlo), sin escribir primero en la prensa, para Neue Zeit ya no había tiempo. Por eso me senté y en dos días escribí 107 páginas de una serie de artículos para el Leipziger Volkszeigtung (...) Schoenlank se entusiasmó mucho. Serán siete artículos (...) lo considera un golpe maestro y una obra maestra de la dialéctica."'3 Se trata de su trabajo sobre "Reforma y revolución" (I 899) donde busca rescatar la esencia de una dialéctica compleja que estudie las contradicciones, negadas por Bernstein, para justificar el reformismo y oponerlo a la revolución.

Luxemburgo es el huracán que sorprende a la dirección del Partido Social Demócrata, al comienzo Kautsky está con Bernstein, cree que se trata de un problema subjetivo, de un malentendido y señala altanero: "La Luxemburgo esa cosa repugnante", porque los ha sacado de su nicho de comodidad de años de desarrollo pacífico. Augusto Bebel consideraba que al negar el socialismo, Bernstein se había

I0 Marmora, Leopoldo. La segunda Internacional y el problema nacional y colonial (Introducción). No.73 cuadernos de pasado y presente. Siglo XXI editores. Méjico. 1978, págs. 16-I8.

I I Kautsky Carlos. Socialismo y política colonial. Una exposición polémica. En la compilación: La Segunda Internacional y el problema nacional y colonial. Segunda parte. No. 74 cuadernos de pasado y presente. Siglo XXI editores. Méjico. 1978, pág. 39.

12 Laschitza, Annelies y RADCZUN Gunter. Rosa Luxemburgo y el movimiento obrero alemán. Editorial de Ciencias Sociales. La Habana. 1977, pág.29.

13 Ibidem., pág.37. 
colocado fuera del partido, pero no le parecía útil discutir ese tema en el congreso. Clara Zetkin y Rosa se oponen rotundamente a aplazar el debate y aprovechan el informe de los parlamentarios para abrir fuego contra el reformismo que planteaba una evolución política ideal, apoyándose en las cooperativas, con algunos cambios pero sin rupturas.

Al tomar la palabra nuestra oradora explicó que un partido sólo puede afirmarse como socialista, si es capaz de dirigir la lucha por las reformas vinculándolas a la lucha por el socialismo. Por eso no puede separarse mecánicamente la reforma de la revolución. Se trata de la lucha por el poder, para destruir el Estado burgués y reemplazarlo por el Estado socialista. Pero había que expresarlo en el programa, por eso dijo:

"Uds. ven que algunos camaradas del partido no tienen la posición del objetivo final de nuestro movimiento, y por ello es necesario, que se exprese clara y terminantemente (...). Además, soy de la opinión de que hay que destruir el Estado. La conquista del poder político sigue siendo el objetivo final, y el objetivo final sigue siendo el alma de la lucha. La clase obrera no puede sostener el punto de vista decadente de los filósofos: "El objetivo final no me importa, el movimiento lo es todo". ${ }^{4}$

El sujeto colectivo se transforma en histórico por los objetivos sistémicos de transformación que se propone y actúa.

Posteriormente, en 1907 ante la imposibilidad de que Hilferding, uno de los primeros economistas que estudiaron el imperialismo, pudiera seguir dictando su curso en la escuela del partido, Rosa es llamada para sucederlo en la cátedra de economía.

Para hacer frente a la crisis del marxismo producida por los teóricos posteriores a la muerte de Marx y Engels, publica en 1913 su obra más importante de economía, sobre "La acumulación de capital", donde encuentra que no sólo existe la acumulación originaria, sino que el capitalismo establece modelos de acumulación de manera continua, analizando de modo similar las crisis económicas que asedian al sistema. Pero en tanto que la acumulación ilimitada era imposible, el fin del sistema estaba cerca. Sin embargo Michael Lowy, señala que esa certeza teórica se hizo más flexible con el advenimiento de la guerra. "La revolución social no es "una certidumbre teórica" a priori, sino una posibilidad objetiva". ${ }^{15}$

De otro lado la teoría de Luxemburgo al ayudar a comprender el papel de la explotación coIonial en la acumulación capitalista mundial, era mal vista por los sectores del PSD que aspiraban a beneficiarse del colonialismo, como lo explicó Lukács. ${ }^{16}$

14 Ibidem., pág.43.

15 Lowy Michael: El Marxismo olvidado (R.Luxemburgo, G.Lukacs). Editorial Fontamara. Barcelona, 1978, pág. 72.

16 Lukacs Georg : Historia y conciencia de clase. Editorial Grijalbo. Barcelona. 1978. Pag. 35. En este libro Lukács, rinde homenaje a Luxemburgo en tres diferentes trabajos: "Rosa Luxemburgo como Marxista", escrito en 1921, "Observaciones críticas a la 
Finalmente en vísperas de la primera guerra mundial y durante su desarrollo, la social democracia internacional se hallaba dividida en tres tendencias teóricas y políticas. La discusión versaba sobre el carácter de la guerra. En primer lugar, los grupos que con la bandera del nacionalismo hablaron de la necesidad de la defensa nacional y terminaron apoyando en cada país beligerante a sus gobiernos respectivos. Se trataba de partidos con una importante tradición parlamentaria que los llevaba a mantener una relación instrumentalista con las masas y que aspiraban a entrar en los gobiernos burgueses como ocurrió en Francia, mediante la desviación que fue señalada como "ministerialismo".

Los grupos de centro que se posicionaron formalmente en contra de la guerra y proponían una paz democrática sin anexiones ni indemnizaciones al final de la guerra. Tesis ingenua en tanto que las anexiones e indemnizaciones eran a la vez la causa y el objetivo final de la guerra. Kautsky fue el abanderado de los centristas.

La tercera posición, donde se ubicaba la tendencia de Luxemburgo, se basaba en las tesis de Lenin, quien criticó duramente a las dos anteriores, demostrando que se trataba de una guerra imperialista por el reparto del mundo. Sin embargo, su posición era la más difícil de comprender, si no se tenían en cuenta los profundos cambios acaecidos en la economía mundial, durante los últimos 30 años, con la formación de las empresas transnacionales monopolistas, que durante la guerra se disputaban las fuentes de materias primas, la mano de obra, los mercados, etc. con el apoyo de sus Estados. Aspecto que transformó el conflicto en una guerra verdaderamente mundial, entre las potencias del centro del sistema mundial, por un nuevo reparto de la periferia colonial.

Si era difícil de comprender el nuevo momento económico, resultaba más difícil poner en práctica una nueva estrategia política adecuada para una crisis tan grave, como una guerra mundial. La consigna que debía llevarse a los soldados en las trincheras debía consistir en una "propaganda en pro de la revolución social, de la conveniencia de volver las armas, no contra sus hermanos, los esclavos a sueldo de otros países, sino contra los gobiernos y partidos reaccionarios y burgueses de todos los países". ${ }^{17}$ Se trataba de la consigna de transformar la guerra mundial en guerra civil. Por esta razón dicha tendencia no puede confundirse con el pacifismo de Tolstoi o Gandhi.

\section{Las discrepancias sobre la huelga general}

Uno de los puntos de discrepancia tenía que ver con el papel que debía asignarse a un nuevo fenómeno que había surgido en el marco de la lucha política de las clases sociales. Se trataba de la huelga política general.

Crítica de la revolución Rusa" y "Observaciones de método acerca del problema de la organización", ambos de 1922 . Una evaluación importante de dichos trabajos aparece en "El Marxismo olvidado" de Michael Lowy. Recientemente Fredric Jameson ha llamado la atención sobre esta obra, bajo el título "Historia y conciencia de clase como un proyecto inconcluso" en el cap. 6 de su "Valencias de la dialéctica", de 2013.

17 Carr, E.H. La revolución Bolchevique (1917-1923) 3. Alianza Editorial. Madrid. 1973, pág.574. 
En realidad en el proceso histórico, la huelga política general había reemplazado las antiguas formas de lucha de las barricadas en las calles. Daniel Guerin refiere la experiencia de dos huelgas generales en Bélgica en mayo de I89| y en abril de 1893, nada menos que para exigir el sufragio universal. Esta novísima forma de lucha generó un debate en el seno de los intelectuales del PSD, en el que participaron Eduard Bernstein, Karl Kautsky, Parvus y Rosa Luxemburgo en Alemania y Jean Jaurés en Francia. A pesar de que se clarificaron algunos elementos como la diferencia entre la huelga reivindicativa y la huelga política, el tema parecía un poco abstracto y quienes debían ponerlo en práctica, el PSD y peor aún, los sindicatos se resistían a aceptarla siquiera como una hipótesis. Esto ocurría porque había una gran prevención contra la idea anarquista de la "huelga general política", por eso en Alemania se habló de la "huelga de masas". En este tema también Parvus va a introducir esta nueva arma escribiendo a favor de usarla ante la amenaza de un golpe militar, que tenía el objetivo de acabar con el sufragio universal, para sacar del juego político al movimiento obrero.

Hasta 1904, en los diversos congresos socialistas, la moción sobre la huelga de masas no había podido aprobarse a pesar del apoyo de Kautsky, para quien resultaba claro que el sufragio universal por sí sólo no bastaría para lograr el triunfo. ${ }^{18}$

Pero los hechos son tozudos, y la guerra ruso japonesa, puso al orden del día una oleada de huelgas que desembocaron en la revolución de 1905 en el centro del imperio de los zares, pero también en la periferia polaca. Rosa Luxemburgo regresa entonces clandestinamente a su patria para vivir su primera experiencia de una revolución de verdad y participa en la insurrección de Varsovia, pero termina en la cárcel como era previsible.

Antes de partir para Polonia Rosa logró que en el congreso de Jena, se aprobara por el PSD, pero luego de una dura batalla. "Cuando se escuchan los discursos pronunciados aquí en los debates (...), uno debe agarrarse la cabeza y preguntarse ¿vivimos verdaderamente en el año de la gloriosa revolución rusa? ${ }^{19}($...). Uds. leen a diario las noticias de la revolución (...), pero parece que no tienen ojos para ver, ni oídos para escuchar (...). Tenemos ante nosotros la revolución rusa, y seríamos unos asnos si nada aprendiéramos de ella". ${ }^{20}$ En primer lugar el poder de huelga de masas.

La experiencia de la revolución polaca genera su trabajo "Huelga de masas, partido y sindicatos". Escrita en Finlandia, luego de salir de la cárcel, gracias al interés y el apoyo brindado por Augusto Bebel.

Pero el momento culminante de esa batalla se va a producir con el estallido de la I Guerra Mundial.

18 Guerin, Daniel. Rosa Luxemburgo o la espontaneidad Revolucionaria. Editorial Utopia Libertaria. Buenos Aires. 2004.

19 Se refiere a la revolución rusa de 1905, inducida por la guerra ruso-japonesa.

20 lbidem., págs.. 45-46. 


\section{Rosa Luxemburgo y la oposición a la Primera Guerra Mundial}

\section{Leer las tendencias de la historia}

En 191 I cuando escribe su texto "Utopías pacifistas" se muestra profundamente pesimista respecto a la paz en el mundo, porque había empezado "la era de las catástrofes, las crisis y las guerras" período que sólo acabó tras la terminación de la segunda guerra mundial, según la periodización del siglo XX, elaborada por E. Hobsbawm.

Uno de los aportes de Luxemburgo es a la comprensión de la situación internacional prebélica y los antecedentes militares de la Primera Guerra Mundial al establecer que:

"En los últimos 15 años tuvimos: en 1895 la guerra entre Japón y China, preludio al surgimiento del imperialismo en Asia Oriental; en I 898 la guerra entre España y Estados Unidos; en I899- 1902, la guerra de los ingleses y los Boers en Sudáfrica; en 1900 la penetración de las potencias europeas en China; en 1904 la guerra rusojaponesa; en 1904- 1907 la guerra de los alemanes contra los Hereros en África; en 1908, la intervención militar de Rusia en Persia; en este momento (1911) la intervención militar de Francia en Marruecos, sin mencionar las incesantes escaramuzas coloniales en África y Asia. La sola enumeración de los hechos demuestra que en el lapso de 15 años no hubo uno solo sin actividad bélica de algún tipo.

Pero más importante aún es la consecuencia de estas guerras. Después de la guerra con China, Japón efectuó la reorganización militar que le permitió emprender 10 años más tarde la guerra contra Rusia y convertirse en la fuerza militar predominante en el Pacífico (...). La guerra contra España impulsó a Estados Unidos a reorganizar su marina de guerra y entrar en la política colonial con los intereses imperialistas en Asia, creándose así el germen del antagonismo de intereses entre Estados Unidos y Japón en el Pacífico".21

Es decir, a caballo entre los dos siglos, los nuevos imperios Alemania y Japón llegaban para disputar la hegemonía global, buscando una nueva repartición del mundo colonial, mediante una enorme cantidad de conflictos locales. Luxemburgo con una gran perspectiva histórica señala el conflicto norteamericano-japonés por la cuenca del pacífico, pero no sólo eso, sino que la guerra hispano-norteamericana de 1898, no solamente posicionaba a Estados unidos en las Filipinas y Guam, sino que con ella empezaban su expansión en América Latina apoderándose de Puerto Rico y de Guantánamo en Cuba.

21 Luxemburgo, Rosa. Obras Escogidas. T.II. Editorial Pluma. Bogotá. 1979, pág. 57. 


\section{La guerra es Chic}

Durante los meses previos a la guerra se creó un ambiente casi festivo en el conjunto de la sociedad. Un crítico latinoamericano nos lo refiere así: "Cuando la atmósfera de Europa, próxima la guerra, se cargó demasiado de electricidad, los nervios de esta generación sensual, elegante e hiperestésica, sufrieron un raro malestar y una extraña nostalgia. Un poco aburridos de vivre avec, douceur, se estremecieron con una apetencia morbosa, con un deseo enfermizo. Reclamaron, casi con ansiedad, casi con impaciencia, la guerra. La guerra no aparecía como una tragedia, como un cataclismo, sino más bien como un deporte, como un alcaloide o como un espectáculo. ¡Oh! La guerra — como en una novela de Jean Bernier, esta gente la presentía y la auguraba--, elle serait trés chic la guerre". 22

Este aspecto festivo sobre la guerra, pero que se convertía en agresivo frente a quienes osaran discrepar siquiera del nacionalismo exagerado, es resaltado también por el gran escritor Stefan Zweig, a quien la guerra lo sorprendió en la frontera de Bélgica en el momento de la invasión alemana, teniendo que instalarse en Viena, que era el centro del imperio austriaco. Nos trae el ejemplo del poeta judío Ernest Lissauer, quien hizo un himno nacionalista, "Canto de odio a Inglaterra", que se cantaba en todas partes y a toda hora, tanto que le mereció un homenaje del káiser. Sin embargo pasada la guerra el poeta tuvo que huir de la Alemania hitleriana. ${ }^{23}$

No se trató solo de casos individuales, en Alemania 93 intelectuales firmaron una proclama de guerra, pero sólo cuatro científicos encabezados por Albert Einstein, firmaron por la paz. En Italia el movimiento de los poetas futuristas encabezados por Dánnuncio y Marinetti se pasaron a la guerra y al fascismo. Por el contrario los futuristas rusos como Mayacovsqui, se entrelazaron con la revolución.

Aun así, a pesar del ambiente tan cargado, la intelectualidad procuró jugar su papel crítico, defensor de la paz, la vida y la cultura, aparece el libro "Más allá de la contienda" de Romain Roland, Nobel de literatura en 1915 quien elabora su propuesta para la acción conjunta internacional de las gentes del arte, la ciencia y la cultura.

Pero la única fuerza que hubiera podido detener la guerra era el movimiento internacional de los trabajadores, en primer lugar el alemán, con su organización y sus I I I parlamentarios. El ultimátum Austriaco contra Serbia había sido planeado por Berlín y Viena, pero los socialdemócratas alemanes creían que su gobierno no estaba inmiscuido, según explicó Kautsky. Por eso intentaron realizar una manifestación el 25 de julio de 19|4, contra Austria que provocaba la guerra pero no tuvo éxito. Pero además con toda ingenuidad se dirigieron al gobierno alemán para que "pusiera en acción toda su influencia sobre el gobierno de Austria, a los fines de preservar la paz". ${ }^{24}$ Es decir cayeron en el juego del gobierno de considerarse inocente.

22 Mariategui, José Carlos. El alma manantial y otras estaciones el hombre de hoy. Editorial Amauta. Lima. 1970, pág. I 5.

23 Zweig, Stefan. El mundo de ayer. Editorial Porrúa. Méjico. 2008, pág. 164.

24 Tarlé, E.V. Historia de Europa. 187| - 1919. Editorial Futuro. Buenos Aires. 1960, pág. 336. 
El 3 I de julio Alemania declaró la guerra contra Rusia, pero el PSD y la clase obrera permanecieron hasta el 4 de agosto: "políticamente pasivas, incapaces y reacias a obstaculizar el desarrollo de los acontecimientos; no quería ni siquiera intentar hacerlo." ${ }^{25}$ La fragmentación del sujeto se constituyó en la peor calamidad de ese momento histórico.

El gobierno y el general Moltke esperaban cumplir al pie de la letra el Plan Schliefen de invadir Francia pasando a través de Bélgica violando su neutralidad y creyendo hasta el día 4 de agosto que Inglaterra no intervendría. Por esa razón "inmensas muchedumbres desfilaron hasta la noche frente al palacio imperial, frente al Reichtag, frente al monumento a Bismarck, frente a las estaciones ferroviarias donde pasaban, uno tras otro, entre marchas militares, los convoyes profusamente abanderados que se dirigían hacia el occidente". ${ }^{26}$ Sin embargo en la tarde el imperio inglés entregó su ultimátum, exigiendo la retirada inmediata porque consideraban que Bélgica era una cabeza de puente para la invasión a Inglaterra.

En Francia había sido asesinado el 3 I de julio Jean Jaurés, el líder más respetado del socialismo, quien había planteado la huelga general contra la guerra. Poincaré entonces decretó la movilización de todas las fuerzas el I de agosto, y el 3 se recibió la noticia que Alemania le decretaba la guerra a Francia. El gigantesco funeral de Jaurés en vez de haber sido una poderosa movilización antibélica, se convirtió "en una singular manifestación de unidad de todas las corrientes políticas y de todas las clases frente al peligro común. Por lo menos así parecía en aquellos días." 27 Los opositores a la guerra en Francia quedaron sepultados junto con Jaurés.

En Alemania las cosas no eran mejores, el único partido que hubiera podido amarrar las manos al Kaiser y al capitalismo alemán, el PSD que tenía I I I parlamentarios aprobó los créditos de guerra, con la única excepción del voto en contra de Karl Liebknecht. Y para completar el juego del nacionalismo vulgar pasaron a darle la mano al emperador. Rosa Luxemburgo le confesó después a su amiga Luisa Kautsky que ese día 4 de agosto quiso suicidarse, ante la felonía y la traición. Pero también ante el grave aislamiento en que quedó su pequeño grupo. El líder histórico del movimiento obrero Augusto Bebel quien se había opuesto a la guerra franco Prusiana en 1870, acababa de morir un año antes del estallido de la I guerra mundial. Sin embargo se contaba con líderes de la talla de Clara Zetkin, de intelectuales como Franz Mehring, compañero de Marx y quien nos legó la primera biografía del genio de Tréveris, construida con la ayuda de su hija Jenny. Con ellos se formó el grupo de "La Internacional", que un tiempo después se transformó en el movimiento de los espartaquistas.

Con la guerra en marcha hacia finales de 1914, Liebknecht, logró separar 19 parlamentarios del bloque socialdemócrata y en marzo ya contaba con 31, de los cuales 29 se abstuvieron de aprobar los nuevos créditos que necesitaba el gobierno y 2 votaron en contra. Se conformó el Partido socialdemócrata Independiente

\footnotetext{
25 Ibidem., pág.338.

26 Ibidem., pág.339.

27 Ibidem., pág.34l.
} 
La actividad antibélica fue perseguida con saña, a principios de 1914 Rosa fue condenada a un año de prisión por una intervención pública realizada en Bockenheim, cerca de Franckfurt, donde llamó a los soldados a no obedecer en caso de que estallase la guerra, pena que cumplió de febrero de 1915 hasta enero de 1916.

\section{Rosa escribe el folleto Junius}

Durante éste primer año de reclusión escribió dos documentos cardinales que salvaron el honor del movimiento obrero alemán, el primero firmado con el seudónimo de Junius, titulado "La crisis de la socialdemocracia" y las "Tesis sobre las tareas de la socialdemocracia internacional", que debía ser leído en el Congreso de los socialista que se realizaría en Zimmerwald contra la guerra, pero el documento no pudo salir de Alemania.

La llegada del $1{ }^{\circ}$ de mayo de 1916 colocó a los espartaquistas ante una decisión muy difícil y muy peligrosa, salir a manifestarse y atenerse a las consecuencias o mantenerse en la parálisis igual que el PSD. Invitaron entonces a los Socialdemócratas independientes, pero éstos no aceptaron el riesgo. La concentración se realizó y llevaron la palabra Rosa y Carlos Liebknecht quien tenía el fuero parlamentario.

Al terminar su discurso contra el conflicto bélico y el emperador alemán, fueron detenidos. Rosa que llevaba seis meses libre volvió a ser recluida y juntos pasaron los dos últimos años de la guerra en prisión, hasta que los albores de la revolución alemana los llevaron de nuevo a la libertad.

El folleto Junius repasa la actitud de la socialdemocracia alemana hasta las vísperas de guerra y encuentra que la importante red de periódicos de que disponía el partido, todos se habían manifestado contra el conflicto y condenaban el ultimátum de Austria a Servia. Sin embargo sobrevino la sesión del reichtag y el informe sobre la invasión a Bélgica, que estaba decidida y en marcha. Además se les presentó el libro blanco que reconocía que Alemania estaba de acuerdo en todo con Austria, para desatar la guerra "con Servia y en última instancia, con toda Europa." La denuncia de Junius va dirigida a establecer cómo fue posible que de "allí todo el bloque socialdemócrata infirió que se trataba de una guerra de defensa contra una invasión extranjera." 28 Y cómo la "contraseña" era evitar que "el despotismo ruso" resultara vencedor. En esencia, cómo se produjo la traición a los principios socialistas.

Por eso Lenin saludó el documento de Junius, como algo muy importante para clarificar las posiciones de la organización política de los trabajadores ante la guerra, pero le hace dos observaciones $1^{\circ}$, no deslindarse claramente del oportunismo de kautsky que tenía una posición centrista muy ambigua y califica esto como un error a la vez teórico y político. Es un error teórico "porque es imposible explicar la" traición" sin ligarla al oportunismo como tendencia que posee una larga historia, la historia de la II Internacional. Esto es un error en el sentido político práctico, porque es

28 Luxemburgo. Op Cit., pág.96. 
imposible comprender la "crisis de la socialdemocracia" ni superarla, sin haber aclarado el sentido y el papel de las dos tendencias: la explícitamente oportunista (Leigen, David, etc) y la solapadamente oportunista (Kautsky y cia.), ${ }^{29}$ Aunque en el texto de Rosa, se caracterizaba bien el conflicto como una guerra imperialista, que había tenido una larga preparación, seguidamente se afirmaba que de allí en adelante ya no podrían existir guerras nacionales, porque todas iban a ser enfrentamientos entre las potencias imperialistas, lo cual fue refutado por Lenin, quien fundamentó entonces, el derecho de las naciones a la autodeterminación. ${ }^{30}$

Finalmente en el Programa espartaquista Luxemburgo acepta la crítica de Lenin y se deslindan definitivamente de la socialdemocracia, para dar el paso hacia un partido de nuevo tipo. Pero es la experiencia avasalladora de la revolución alemana la que lleva a Rosa Luxemburgo a cambiar de opinión por lo menos en dos temas fundamentales: Aquel del instrumento político necesario para encauzar todo el proceso y en el papel prioritario de los consejos. En ambos temas acepta al final de su vida las tesis de Lenin que habían conducido al triunfo del mundo del trabajo y la cultura en la patria de Dovstoievski y León Tolstoy.

\section{La revolución alemana}

La revolución alemana producida por el hambre y el impacto de la derrota en la guerra, era evidente para todos hacia octubre de 1918. Sin embargo ocurrió algo que hizo reaccionar a los miles de hombres que habían soportado estoicamente durante cuatro años la muerte y el sufrimiento sin límites. Los generales Hindenburg y Ludendorff hicieron un llamamiento al ejército alemán para que resistieran hasta el final. También, en el puerto de Kiel, donde se concentraba la flota, se enteraron de que pronto llegaría la orden para iniciar una ofensiva suicida contra Inglaterra. Pero ya eran suficientes 2 millones de soldados y marineros alemanes muertos. La rebelión empezó el 28 de octubre en el primer acorazado y luego se extendió a toda la flota y en los días siguientes llegó a Hamburgo y Lubeck y a gran parte del país incluido Berlín. En grandes asambleas formaron consejos de marineros y soldados.

También en octubre se llevó a cabo la Conferencia nacional de los espartaquistas, la Reichconferenz, donde se decidió impulsar los Consejos de campesinos, obreros y soldados, en oposición al parlamentarismo y llamó a la Unidad de Acción, con los grupos de izquierda como el de Radek y los consejos de Bremen. Con los llamados "capitanes revolucionarios": E. Dumig y R. Muller, sindicalistas del USPD, y Kurt Eisner quien trabajaba por los Consejos pero creía que podían coexistir con el parlamento. Previamente de manera audaz los espartaquistas se habían unido al Partido de los socialdemócratas independientes USPD, para avanzar en la construcción del sujeto colectivo. ${ }^{31}$

29 Lenin. V. Sobre el folleto Junius. Obras completas. T.30. Editorial Progreso. Moscú. 1985, pág.3.

30 Lenin. V. Balance de la discusión sobre la autodeterminación. T.30, págs.7 y ss.

31 Collotti Enzo: Alemania de los consejos. En el libro: Consejos obreros y democracia socialista. Pasado y Presente $N^{\circ} 33$. Gerratana et al. Buenos Aires, 1972. 
Pero los acontecimientos se aceleraban y el 3 de Noviembre de 1918, la revolución se generaliza contra la muerte masiva e inútil. Rosa Luxemburgo y Karl Liebnecht han salido de la cárcel el 21 de octubre y se han puesto al frente de la organización de los consejos, el 9 de noviembre el poderoso movimiento de masas impone la renuncia y huída cobarde del emperador. En Berlín, Liebnecht le habla a la multitud desde el propio palacio imperial. El socialdemócrata Scheideman tiene que hablar desde un balcón del reichtag y se ve obligado a proclamar la república. El I I de noviembre el general Hindenburg tiene que aceptar el armisticio humillante para el imperialismo alemán. ${ }^{32}$

Empieza a producirse algo similar a la dualidad de poderes que se dio en el período de la revolución de febrero hasta la revolución de octubre de 1917, en Rusia, pero en Alemania, los trabajadores no lograron desencadenar toda su potencia y asumir el poder, porque las ciudades y regiones que estaban en manos de los consejos, se hallaban aisladas ya que no se había logrado construir el instrumento político que centralizara toda la acción.

Mientras tanto la mayoría socialdemócrata ahora en el gobierno, con Ebert como canciller se opuso totalmente a la revolución. Desde allí la consigna del PSD era "orden o derrumbe".

La acciones populares se extienden hasta enero de 1919, son tres meses cortos, cuando una provocación del gobierno, produce una insurrección espontánea que no tiene posibilidades de salir victoriosa, lo que facilita la generalización de la represión por parte del partido socialdemócrata, por medio de su ministro de defensa Noske, quienes deciden exterminar la dirección del nuevo movimiento, ejecutan la detención-desaparición de Rosa y Liebnecht, dos meses después le quitan la vida a Leo Jogiches y a los más destacados líderes del movimiento consejista como Kurt Eisner y Levinés.

Los consejos revolucionarios locales fueron derrotados en Bremen el 4 de febrero y en Baviera el 3 de mayo de 1919, seis meses después del levantamiento de la flota, terminaba la revolución alemana. Todo el poder pasó a la Asamblea nacional de Wiemar y posteriormente un artículo de la Constitución, legalizaba los consejos, pero reduciéndoles sus funciones a un nivel puramente sindical. Karl Korch pensó revolucionarlos y todavía en 1923 se libró en Turingia la última batalla.

\section{Conclusiones}

La figura más importante de todo este proceso de resistencia a la guerra en Alemania y Polonia fue Rosa Luxemburgo, quien estuvo a la altura de Lenin y Trostski en la Rusia de los zares, puesto que su trabajo, sus debates, y documentos sirvieron para cohesionar ideológica y políticamente al movimiento obrero consciente, y aunque no logró una mayoría estable, para detener la conflagración y eventualmente avanzar a la revolución socialista en Alemania, sí logró momentos de gran unidad en la acción, que obtuvieron conquistas para el pueblo alemán, como el derrocamiento del emperador, uno de los principales responsables de la guerra. Y porque jamás dio tregua al guerrerismo, desarrollando una intensa

32 Tarlé E. : Historia de Europa. 187 | - 1919. Editorial Futuro. Buenos Aires. 1960, págs..495 y siguientes. 
actividad de propaganda antibélica. Finalmente el capital financiero, los junkers y sus expresiones políticas y los grupos de la derecha incrustados en la socialdemocracia, a quienes había combatido toda su vida, decidieron acabar con su preciosa vida, pero no pudieron quitarle actualidad a sus ideas. Nunca se ha borrado el recuerdo de su valiente lucha contra la guerra mundial, comenzando por la impronta que dejó en la poderosa constelación de intelectuales de los años 20 a la segunda conflagración mundial.

Si retomamos la temática de Luxembugo en el doble aspecto de la reforma y la revolución, el PSD alemán desperdició la oportunidad de poner en práctica su programa socialista. En primer lugar cuando la poderosa movilización de masas derrocó al Kaiser y los consejos perdieron la oportunidad de asumir todo el poder. El cambio de las clases en el poder hubiera significado una ruptura con el capitalismo y el comienzo de la revolución socialista por primera vez en un país industrializado. Como esto no ocurrió, el PSD quedó "prisionero de una lógica tan perversamente conservadora, al punto de ni siquiera aprovechar el espacio político existente, para realizar las reformas democráticas propuestas por su programa. Como todos sabemos la historia se ha vengado más tarde de tanta falta de osadía." 33 (Loureiro, 2005: 226). Es decir no hubo ni reforma ni revolución y esto abrió el camino a la dictadura nazi y a la II guerra mundial. Toda una triste enseñanza histórica.

La fuerza de Luxemburgo se halla en su pensamiento crítico, no sólo contra quienes intentaban revisar de manera perversa el marxismo, sino que también ensayó la "Crítica de la revolución rusa", trabajo elaborado en la cárcel, sin la información completa y necesaria para una crítica de tal magnitud. Por eso allí al lado de la defensa de la necesidad de la democracia en la revolución, aspecto que explica con toda nitidez y solvencia, no vislumbra lo más profundo de la revolución rusa: la superación del modelo democrático tradicional, por la nueva democracia soviética, es decir la democracia desde abajo, desde los consejos de campesinos, obreros y soldados, el primer experimento de democracia popular, comunitaria. Pero luego, al salir de la cárcel y contar con una información más exacta, no duda en proponer ese nuevo modelo de democracia para Alemania, que ya los marineros, obreros y soldados empezaban a poner en práctica: la idea de una república de los consejos.

Si para la época actual aceptamos la tesis de Hobsbawm, de que nos encontramos en un período similar al de la primera mitad del siglo $X X$, es decir, de crisis, guerras y catástrofes, vale la pena volver sobre la obra y el actuar en la historia de esta ejemplar mujer, que nos mostró los caminos interrelacionados de la reforma y la revolución, de la paz y los Derechos Humanos.

\section{Bibliografía}

ARENDT HANNA: "Walter Benjamin; Bertolt Brecht; Hermann Broch; Rosa Luxemburgo". Editorial Anagrama. Barcelona. 1968.

33 Loureiro, Isabel. El pensamiento y la acción de Rosa Luxemburgo. En pensamiento y acción por el socialismo. Gambina, Julio et-al (Compiladores) Fundación Investigaciones Sociales y Políticas - FISYP. Buenos Aires. 2005, pág.226. 
BERNSTEIN, BAX, KAUTSKY, RENNER: "La Segunda Internacional y el problema nacional y colonial (primera parte)" Cuadernos de pasado y presente No.73. Méjico. 1978.

CALWER, KAUTSKY, BAUER, STRASSER, PANNEKOEK: "La Segunda Internacional y el problema nacional y colonial (segunda parte)" Cuadernos de pasado y presente No.74. Siglo XXI Editores. Méjico. 1978.

CARR E. H.: "La revolución bolchevique (1917-1923) 3". Alianza Editorial. Madrid. 1973.

DROZ JACQUES: “Historia general del socialismo. De 1875 a 1918”. Ediciones Destino. Colección Destinolibro, Volumen 225. Barcelona. 1985.

ELIAS NORBERT: "La sociedad cortesana”. Fondo de Cultura Económica. Méjico. 1996.

GAY PETER: La cultura de Weimar. Paidós. Contextos. Madrid, 2011.

GERRATANA, MAGRI, SALVADORI, BOURDET, FERRI, FOA, COLLOTI, GARAVINI, GRAMSCI "Consejos obreros y democracia socialista". Cuadernos de pasado y presente No.33. Buenos Aires. 1972.

GUERIN DANIEL: "Rosa Luxembug o la espontaneidad revolucionaria”. Editorial Utopía Libertaria. Buenos Aires. 2004.

HOBSBAWM ERIC: "La barbarie: guía del usuario. En: Sobre la historia". Editorial Crítica. Barcelona. 1998. : Historia del Siglo XX. Editorial Crítica, Grijalbo Mondadori. Buenos Aires. 1998.

KOFLER LEO: "Contribución a la historia de la sociedad burguesa". Amorrortu Editores. Buenos Aires. 197 I.

LASCHITZA ANNELIES, RADCZUN GUNTER: "Rosa Luxemburgo y el movimiento obrero alemán". Editorial de Ciencias Sociales, la Habana. 1977.

LENIN: "Sobre el folleto Junius". Obras Completas T.30, Editorial Progreso. Moscú. 1985.

LENIN: "Balance de la discusión sobre la autodeterminación". Obras Completas T.30 Editorial Progreso. Moscú. 1985.

LIEBKNECHT CARLOS: “Militarismo, guerra, revolución”. Ediciones Roca No.4I. Méjico. 1974.

LOWY MICHAEL: "El marxismo olvidado R. Luxemburg, G. Lukacs". Editorial Fontamara. Barcelona. 1978.

LOUREIRO ISABEL: "El pensamiento y la acción de Rosa Luxemburg. En Pensamiento y acción por el socialismo. Gambina Julio, Rajland Beatriz, Campione Daniel (compiladores)". Fundación Investigaciones Sociales y Políticas - Fisyp. Buenos Aires. 2005.

LUKACS GEORG: "Historia y conciencia de clase". Editorial Grijalbo, Instrumentos I.Barcelona. 1978.

LUXEMBURGO ROSA: "Obras escogidas". En dos Tomos. Editorial Pluma. Bogotá. 1979.

MARIATEGUI JOSE CARLOS: "El alma matinal y otras estaciones del hombre de hoy". Editorial Amauta. Lima. 1970.

MARMORA LEOPOLDO: "La Segunda Internacional y el problema nacional y colonial (Introducción)". No.73 cuadernos de pasado y presente. Siglo XXI Ediciones. Méjico. 1978. 
MAYER ARNO: "La persistencia del antiguo régimen. Europa hasta la gran guerra". Alianza Editorial. Madrid. 1984.

PARVUS, MEHRING, LUXEMBURG, KAUSTSKY, VANDERVELDE: Debate sobre la huelga de masas. Cuadernos de P y P" No.62. Córdoba. 1975.

PHELAN ANTHONY: El dilema de Weimar. Los intelectuales en la república de Weimar. Edicions Alfons el magnánim.IVEI, Valencia.1990.

ROLAND ROMAIN: "Más allá de la contienda." Editorial Nórdica. Madrid. 2014.

SCHUTRUMPF JORN: "Rosa Luxemburg o el precio de la libertad". Fundación Rosa Luxemburgo.Editorial. Karl Dietz Berlín 2007.

TARLÉ E. V.: "Historia de Europa. I87I - 1919". Editorial Futuro, Buenos Aires. 1960.

TASSIN ETIENNE: De la subjetivación política.

Althusser/Ranciére/Foucault/Arendt/Deleuze. Inicio. Revista N 43.

ZWEIG STEFAN: "El mundo de ayer". Editorial Porrúa, Méjico. 2008. 